\title{
ORIENTATION MEASUREMENT WITH GYROTHEODOLITE
}

\author{
Vladimír BEZDÍČEK ${ }^{1}$, Rostislav DANDOŠ2* ${ }^{*}$, Miroslav KONEČNÝ ${ }^{3}$, Juraj KOTRBANEC ${ }^{4}$, \\ Tomáš KRÁL ${ }^{5}$, Andrea WLOCHOVÁ 6 \\ ${ }^{1-4}$ Department of Geodesy and Mine Surveying, VŠB - Technical University of Ostrava, \\ 17. listopadu 15, CZ 70833 Ostrava, Czech Republic \\ ${ }^{5}$ Department of Mining Engineering and Safety, VŠB - Technical University of Ostrava, \\ 17. listopadu 15, CZ 70833 Ostrava, Czech Republic \\ ${ }^{6}$ Department of Foreign Languages, VŠB - Technical University of Ostrava, \\ 17. listopadu 15, CZ 70833 Ostrava, Czech Republic
}

Received 26 May 2018; accepted 20 September 2018

\begin{abstract}
The article deals with the principle of using gyrotheodolite in connection and orientation measurements. It describes orientation measurements with gyrotheodolite, provides basic information about the device and explains how it works. The first part describes gyrotheodolite and methods of determining astronomical true north. The workflow for measurement and subsequent data processing is described below. In the second part, two orientation measurements are described and processed. Finally, the accuracy achieved and the possibility to use the device for activities other than mine measurement are assessed.
\end{abstract}

Keywords: connection and orientation measurements, basic orientation line, gyrotheodolite, gyro station, instrument constant, mining measurement baseline, astronomical north.

\section{Introduction}

Connecting and orientation measurement is one of the most important and most difficult tasks of the mine meter and mine measurement in general. The purpose of the connection and orientation measurement is to transfer the binding reference system from the surface to the underground, i.e. to determine the coordinates of the so-called basic orientation line, hereinafter BOL. The BOL points are the mining fundamental horizontal control, so they should be determined as accurately as possible. Each of the various ways of connection and orientation is specific with respect to its time-consuming character, necessary equipment, subsequent processing, and achievable accuracy.

\section{Gyrotheodolite}

The main advantage of gyrotheodolite is the determination of astronomical azimuth in real time, independent of the ground force fields (generally magnetic fields, electric fields and others). Gyrotheodolite determines the direction of the local meridian. Gyrotheodolite has much higher accuracy (around 15') compared to the surveyor's compass (about $1^{\prime}$ ), and its mechanical principle is not influenced by the already mentioned often undetectable magnetic influences that could lead to significant errors when determining the direction with the surveyor's compass. The main component of the gyrotheodolite is the gyro wheel. The gyro wheel is modified to have three degrees of freedom and to be able to move independently in space. It consists of a balanced electric motor where the rotor axis is also the axis of the gyro wheel. Due to the ground rotation, the axle of the rotated gyro wheel turns into the direction of the local meridian around which it culminates (precessional movement). The gyro wheel is usually hinged on the torsion tape to form a pendulum or is enclosed in a hollow casing and floats in a container with a liquid. The gyro wheel rotates at about 15,000 to 30,000 revolutions per minute. In geodetic applications, combinations of the theodolite with a pendulum gyro wheel suspended on a torsion tape are most commonly used. The gyro wheel operates on the principle of an induction motor powered by the three-phase current, the

${ }^{*}$ Corresponding author. E-mail: rostislav.dandos@vsb.cz

This is an Open Access article distributed under the terms of the Creative Commons Attribution License (http://creativecommons.org/licenses/by/4.0/), which permits unrestricted use, distribution, and reproduction in any medium, provided the original author and source are credited. 
motors are either synchronous or asynchronous. The engine rotates to the required speed for a certain amount of time depending on the gyro wheel design. As the gyrotheodolite gyro wheel turns to the nearest intersection of the unstable Earth rotation axis, its area application is also limited. Manufacturers declare local azimuth determination up to $75^{\circ}$ parallel with an accuracy of $10-20^{\prime \prime}$ (Bezdíček, 2016).

Gyrotheodolites are divided according to their design, either into planting or permanently linked ones (Figure 1). In the case of the planting gyrotheodolite, the gyro wheel is hung on the torsion tape as a pendulum, and the theodolite is attached in the form of a gyro extension. Although it is more susceptible to external influences such as vibrations and wind conditions, the theodolite is normally usable for further measurements after removing the gyro extension. In the case of the permanently linked gyrotheodolite, the gyro wheel can be enclosed in a hollow casing and moves in a container with a liquid. This construction is more resistant to external influences, but the device is heavier, bigger, more difficult to handle and further use is complicated (Bezdíček, 2016).

\section{Methods of determining astronomical true north by gyrotheodolite}

Two best-known methods are used to determine astronomical true north. The first method is the so-called Follow method and the second method is called the Time method. They can be used for almost all gyrotheodolites (gyro stations). They are the most commonly used methods at all for their simplicity and accuracy.

The Follow method principle (Figure 2) is based on the careful rotation of the gyro station behind the floating index. When the floating index reaches the culminating point or turning point, a horizontal angle is automatically recorded. The flow of the pivots should be smooth and gradually subdued. Based on experience, the first value of the culminating point is omitted as it is affected by the release of the gyro suspension to the free position. When recording two consecutive reversal points, we can determine the azimuth to true north (TN) with a standard deviation of $20^{\prime \prime}$. When we observe three consecutive reversal points, we determine the azimuth to true north (TN) with a standard deviation of $15^{\prime \prime}$. For this method, the instrument must be directed to true north with an accuracy of $\pm 2^{\circ}$ (Sokkia Instruction, n.d.).

In the case of the Time method, the gyro station is without movement. The calculation is based on the amplitude of the right and left reversal points, the time of the floating index passing through the centre of the scale and its return. This measurement is very accurate, but it is more demanding to prepare. Verification of the zero position of the torsion tape must be performed. If three or more consecutive values the floating index passage are recorded, it is possible to determine the azimuth to true north with a deviation of $15^{\prime \prime}$. In the Time method, the instrument must be directed to true north with an accuracy

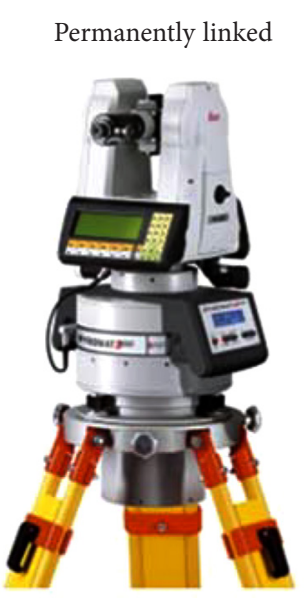

Gyromat 3000

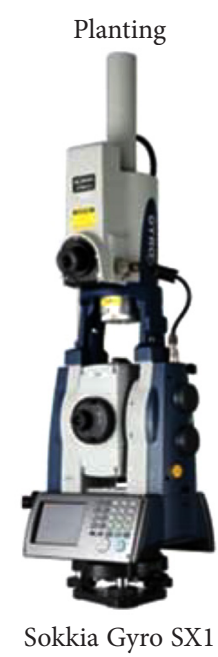

Figure 1. Types of gyro stations

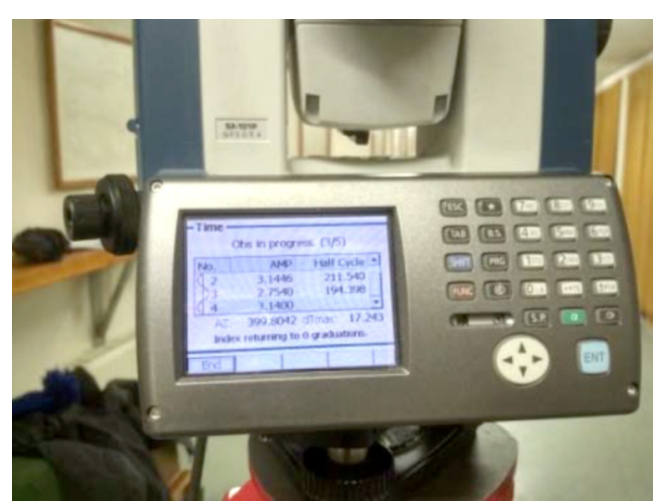

Figure 2. Example of the Follow method

of $\pm 2^{\prime}$. In the past, this measurement was complicated and sufficiently accurate time gauges were not available, but eventually, improvements have been made (Sokkia Instruction, n.d.).

\section{Direction measurement procedure}

Determining astronomical true north takes place in several measurement phases. The measurement was performed using the Sokkia GYRO X II automatic gyro station.

The first phase is to determine the constant of the device $k_{g}$ on a line with known coordinates in the given coordinate system. For these purposes, the mining measurement baseline is used (hereinafter referred to as MMB), which is located in the main building A of VŠB-TUO on the first floor.

Figure 3 shows that the MMB is determined by 3 points with known coordinates in a valid coordinate system. The actual measurement takes place in three phases. Using the optical centring device, the tripod, on which the total station will be mounted, is centred and horizontally aligned under the point. Consequently, the gyro extension is installed, and after the necessary cabling is connected, levelling is rechecked again to make sure that it has not 


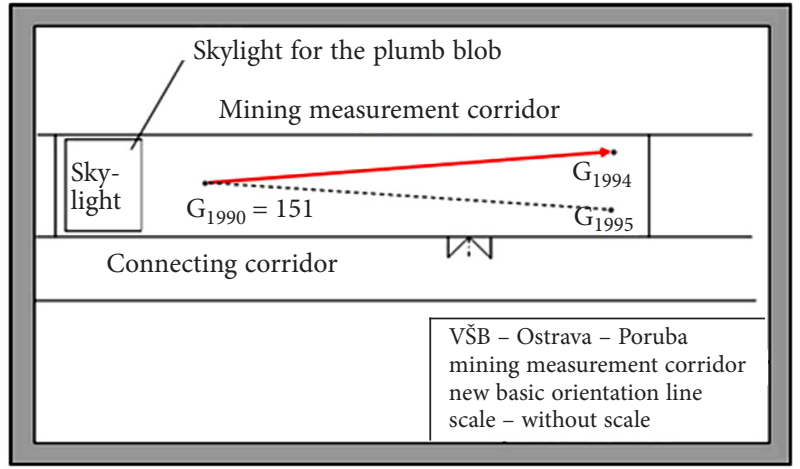

Figure 3. Mining measurement base at VŠB-TUO (Bezdíček, 2016)

been disrupted. Then, the condition of the torsion tape is checked to see if it has not been damaged or affected during transportation. The check is followed by an approximate determination of true north. For a rough determination of $\pm 2^{\circ}$, a surveyor's compass is used, followed by the Follow method of at least two consecutive points of reversal. After an approximate determination of north, the Time method is used to determine true north, and the azimuths of the respective MMB points are measured (Figure 4). The Time method is repeated at least twice, the difference of the specified azimuths must not exceed the difference of $20^{\prime \prime}$. After the measurement is completed, it is possible to calculate the relevant device constant.

The second phase is the determination of the azimuth on the line which is being determined (in the mine). Before assembling and starting the device, it is first necessary to check the concentration of methane near the stand to prevent an explosion caused by electrical discharge. The measurement procedure at the line which is being determined is the same as for the MMB. The deviation between the maximum and minimum values the azimuth determined must not exceed $20^{\prime \prime}$.

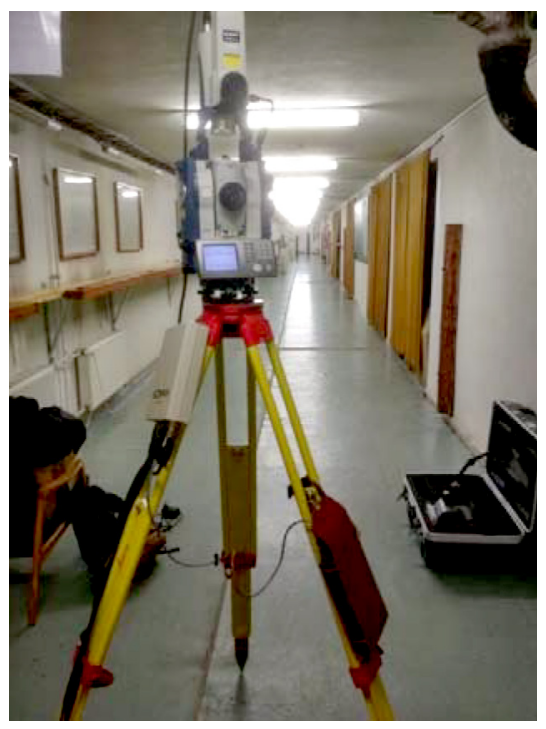

Figure 4. Determination of the device constant at the MMB
The third and the last phase is to re-check the constant of the device at the MMB in the shortest possible time after the measurement on the line which is being determined. The reason is that other processes that are changing over time affect by the determination of the local meridian. This is primarily the movement of the Earth's Axis (Precession and Nutation), high tide and low tide, neighbouring planets, cosmic bodies, solar eruptions, tsunamis, volcano eruptions, and other processes affecting the movement of the Earth's body. All these processes are unpredictable, and they can invalidate measurements. If there were any global changes such as earthquakes or volcano eruptions throughout the measurement, the entire measurement could be invalidated, and the whole process would have to be repeated.

This completes fieldwork related to orientation measurements. For the determination and calculation of the $\mathrm{BOL}$, it is still necessary to obtain the approximate coordinates of the line which is being determined, most often by connecting from the surface. Connecting measurements are performed by conducting one plumb blob through one pit. This is a very complex process, with respect to preparing, as well as processing the obtained data (Černota \& Staňková, 2014).

\section{Processing of measured data using the gyro station}

For data processing, it was first necessary to calculate the constant of the deployed gyro station. The instrument constant is calculated according to the following equation:

$$
k_{g}=\sigma_{0}-A_{0},
$$

where $\sigma_{0}$ is the MMB bearing and $A_{0}$ is the azimuth measured by the gyro station (Novák \& Hánek, 1995).

It is followed by the determination of the azimuth on the line which is being determined in the underground. The BOL bearing is then calculated from the following equation

$$
\sigma=A+k_{g}+\Delta_{\delta}+\Delta_{c}
$$

where $A$ - the azimuth determined for BOL; $\sigma$ - BOL bearing; $k_{g}$ - the verified instrument constant; $\Delta \delta$ - the correction due to the change in the deflection angle; and $\Delta c$ - the correction due to the change in the meridian convergence. The correction $\Delta \delta$ was neglected. It is only considered in cases where BOL points have a significant difference in altitudes (Novák \& Hánek, 1995).

The correction due to the change in the meridian convergence $\Delta_{c}$ is calculated from the formula

$$
\Delta_{c}=\gamma_{2}-\gamma_{1} \text {, }
$$

where $\gamma_{2}$ - the meridian convergence at the BOL point; $\gamma_{1}$ - the meridian convergence at the MMB point (Novák \& Hánek, 1995).

Finally, the constant of the deployed gyro station, which was verified by the MMB, was calculated according to equation (1) again. 


\section{Determining the accuracy of the measurements}

The resulting accuracy of the bearing on the basic orientation line determined by the Sokkia GYRO X II gyro station is based on the equation:

$$
m_{x} \sigma= \pm \sqrt{\left(m_{x} \sigma_{0}\right)^{2}+\left(m_{x} A_{0}\right)^{2}+\left(m_{x} A\right)^{2}}
$$

where $m_{x} \sigma$ - the mean error of the BOL bearing arithmetic mean; $m_{x} \sigma_{0}$ - the mean error of the initial MMB bearing arithmetic mean; $m_{x} A_{0}$ - the mean error of the arithmetic mean of the azimuth determined at the initial MMB; $m_{x} A$ the mean error of the arithmetic mean of the azimuth determined at the BOL.

The mean error of the arithmetic mean of the initial MMB $m_{x} \sigma_{0}$ is determined by the dependence on the precision of the angular measurement in the trigonometric network (about 1 mgon) (Neset, 1967).

The mean error of the arithmetic mean of the azimuth determined at the initial MMB $m_{x} A_{0}$ is calculated from the formula:

$$
m_{x} A_{0}= \pm \sqrt{\frac{[v v]}{n(n-1)}},
$$

where $v$ is the correction, the value of the difference between the measured value and the average value.

The mean error of the arithmetic mean of the azimuth determined at the BOL $m_{x} A$ is calculated using the following equation:

$$
m_{x} A= \pm \sqrt{\frac{[v v]}{n(n-1)}},
$$

where $v$ is the correction, the value of the difference between the measured value and the average value (Neset, 1967).

\section{The orientation of the line at the ČSM Mine}

The measurements took place on 29 and 30 September 2016. The starting base was the MMB in the VSB - Technical University of Ostrava campus. Table 1 shows the determined and validated gyrostatic constants. The MMB also measured the check angle between the points $G_{1994}$ and $G_{1995}$, see Figure 3. The azimuth is related to the point $\mathrm{G}_{1994}$.

Table 1. Gyro station constants

\begin{tabular}{|c|c|c|c|c|c|}
\hline Point & Date & Time & $\begin{array}{c}A_{0} \\
\text { azimuth } \\
\text { /gon/ }\end{array}$ & $\begin{array}{c}\text { Check } \\
\text { angle } \\
\text { /gon/ }\end{array}$ & $\begin{array}{c}K_{g} \\
\text { constant } \\
\text { /gon/ }\end{array}$ \\
\hline \multirow{5}{*}{$\mathrm{G}_{1990}$} & $29 / 9 / 2016$ & $8: 15$ & 23.0161 & 1.6077 & 205.3454 \\
\cline { 2 - 6 } & $29 / 9 / 2016$ & $8: 47$ & 23.0189 & 1.6066 & 205.3426 \\
\cline { 2 - 6 } & $29 / 9 / 2016$ & $9: 20$ & 23.0159 & 1.6078 & 205.3491 \\
\cline { 2 - 6 } & $30 / 9 / 2016$ & $8: 32$ & 23.0159 & 1.6074 & 205.3456 \\
\cline { 2 - 6 } & $30 / 9 / 2016$ & $9: 05$ & 23.0155 & 1.7076 & 205.3461 \\
\hline
\end{tabular}

In Table 2, the parameters are determined at point $\mathrm{G}_{1990}$, which is the starting point of the MMB. The bearing was calculated from the known coordinates of the points $\mathrm{G}_{1990}$ and $\mathrm{G}_{1994 \text {. }}$

Table 2. Calculation of the bearing

\begin{tabular}{|c|c|c|c|}
\hline Point & $\begin{array}{c}K_{g} \text { constant } \\
\text { /gon/ }\end{array}$ & $\begin{array}{c}\gamma \text { convergence } \\
\text { /gon/ }\end{array}$ & $\begin{array}{c}\sigma_{0} \text { bearing } \\
\text { /gon/ }\end{array}$ \\
\hline $\mathrm{G}_{1990}$ & 205.3457 & 5.5443 & 228.3615 \\
\hline
\end{tabular}

The following Tables 3 and 4 show the azimuths recorded during each measurement. As already mentioned, the MMB is determined by three points with the starting point $\mathrm{G}_{1990}$. The BOL in the underground was determined by two points, with the starting point $\mathrm{G}_{5693}$. The BOL azimuth refers to the point $\mathrm{G}_{5692}$. Additionally, there are corrections in the tables for calculating the mean errors in the specified azimuths.

Table 3. Recorded azimuths $\mathrm{A}_{0}$ and corrections

\begin{tabular}{|c|c|c|c|c|c|}
\hline Point & Date & Time & $\begin{array}{c}A_{0} \\
\text { azimuth } \\
\text { /gon/ }\end{array}$ & $\begin{array}{c}v \\
\text { /gon/ }\end{array}$ & $\begin{array}{c}v v \\
\text { /gon/ }\end{array}$ \\
\hline $\mathrm{G}_{1990}-\mathrm{G}_{1994}$ & $29 / 9 / 2016$ & $8: 15$ & 23.0161 & -0.87 & 0.75 \\
\hline $\mathrm{G}_{1990}-\mathrm{G}_{1994}$ & $29 / 9 / 2016$ & $8: 47$ & 23.0189 & 1.93 & 3.74 \\
\hline $\mathrm{G}_{1990}-\mathrm{G}_{1994}$ & $29 / 9 / 2016$ & $9: 20$ & 23.0159 & -1.07 & 1.14 \\
\hline $\mathrm{A}_{0} / 3$ & & & 23.0170 & {$[\mathrm{vv}]$} & 5.63 \\
\hline
\end{tabular}

Table 4. Recorded azimuths A and repairs

\begin{tabular}{|c|c|c|c|c|c|}
\hline Point & Date & Time & $\begin{array}{c}A \\
\text { azimuth } \\
\text { /gon/ }\end{array}$ & $\begin{array}{c}v \\
\text { /gon/ }\end{array}$ & $\begin{array}{c}v v \\
\text { /gon/ }\end{array}$ \\
\hline $\mathrm{G}_{5693}-\mathrm{G}_{5692}$ & $29 / 9 / 2016$ & $14: 10$ & 317.1314 & -0.87 & 0.75 \\
\hline $\mathrm{G}_{5693}-\mathrm{G}_{5692}$ & $29 / 9 / 2016$ & $14: 42$ & 317.1325 & 0.23 & 0.05 \\
\hline $\mathrm{G}_{5693}-\mathrm{G}_{5692}$ & $29 / 9 / 2016$ & $15: 15$ & 317.1329 & 0.63 & 0.40 \\
\hline $\mathrm{A} / 3$ & & & 317.1323 & {$[\mathrm{vv}]$} & 1.21 \\
\hline
\end{tabular}

Table 5 lists the parameters needed to calculate the mean error of the arithmetic mean of the Uniform Trigonometric Cadastral Network (UTCN) BOL bearing.

Table 5. Parameters for calculating the mean error

\begin{tabular}{|c|c|c|}
\hline $\begin{array}{c}m_{x} A_{0} \\
/ \text { mgon/ }\end{array}$ & $\begin{array}{c}m_{x} A \\
\text { /mgon/ }\end{array}$ & $\begin{array}{l}m_{x} \sigma_{0} \\
\text { /mgon/ }\end{array}$ \\
\hline \pm 0.97 & \pm 0.45 & \pm 0.10 \\
\hline
\end{tabular}

Table 6 lists the resulting orientation measurement values the point $\mathrm{G}_{5693}$. 
Table 6. Resulting orientation measurement values

\begin{tabular}{|c|c|c|c|c|}
\hline Point & $\begin{array}{c}A \text { azimuth } \\
\text { /gon/ }\end{array}$ & $\begin{array}{c}\gamma \text { convergence } \\
\text { /gon/ }\end{array}$ & $\begin{array}{c}\sigma \text { bearing } \\
\text { /gon/ }\end{array}$ & $\begin{array}{c}m_{x} \sigma \\
\text { /gon/ }\end{array}$ \\
\hline $\mathrm{G}_{5693}$ & 317.1323 & 5.2157 & 122.1493 & \pm 1.07 \\
\hline
\end{tabular}

By orientation measurement, the UTCN BOL bearing (size 122.1493 gon) with the mean error of the arithmetic mean \pm 1.07 mgon was determined at the point $G_{5693}$.

\section{The orientation of the line in the VŠB Planetarium complex}

The measurements took place on 15 and 16 February 2018. The starting base was the MMB in the VSB - Technical University of Ostrava campus. Table 7 shows the determined and validated gyrostatic constants. The MMB also measured the check angle between the points $\mathrm{G}_{1994}$ and $\mathrm{G}_{1995}$, see Figure 3. The azimuth is related to the point $\mathrm{G}_{1994}$.

Table 7. Gyro station constants

\begin{tabular}{|c|c|c|c|c|c|}
\hline \multirow{2}{*}{ Point } & Date & Time & $\begin{array}{c}\mathrm{A}_{0} \\
\text { azimuth } \\
\text { /gon/ }\end{array}$ & $\begin{array}{c}\text { Check } \\
\text { angle } \\
\text { /gon/ }\end{array}$ & $\begin{array}{c}\mathrm{K}_{\mathrm{g}} \\
\text { constant } \\
\text { /gon/ }\end{array}$ \\
\hline \multirow{4}{*}{$\mathrm{G}_{1990}$} & $15 / 2 / 2018$ & $10: 10$ & 22.8007 & 1.6077 & 205.5608 \\
\cline { 2 - 6 } & $15 / 2 / 2018$ & $10: 37$ & 22.8029 & 1.6074 & 205.5586 \\
\cline { 2 - 6 } & $15 / 2 / 2018$ & $11: 24$ & 22.8008 & 1.6079 & 205.5607 \\
\cline { 2 - 6 } & $16 / 2 / 2018$ & $8: 02$ & 22.8000 & 1.6078 & 205.5615 \\
\cline { 2 - 6 } & $16 / 2 / 2018$ & $8: 29$ & 22.8012 & 1.6072 & 205.5603 \\
\hline
\end{tabular}

In Table 8, the parameters are set at the MMB starting point $\mathrm{G}_{1990}$. The bearing was calculated from the known coordinates of the points $\mathrm{G}_{1990}$ and $\mathrm{G}_{1994}$.

The following Tables 9 and 10 show the azimuths recorded during each measurement. The BOL on the surface (Figure 5) was determined by two points, with the starting point $\mathrm{G}_{1003}$.

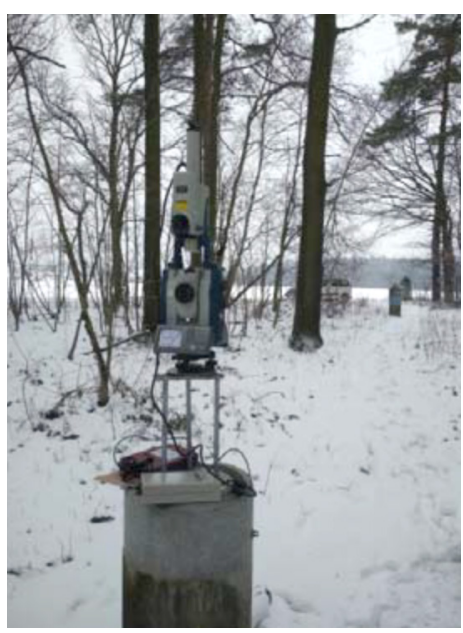

Figure 5. Gyro station at $\mathrm{G}_{1003}$
Table 8. Parameters specified at the MMB starting point

\begin{tabular}{|c|c|c|c|}
\hline Point & $\begin{array}{c}K_{g} \text { constant } \\
\text { /gon/ }\end{array}$ & $\begin{array}{c}\gamma \text { convergence } \\
\text { /gon/ }\end{array}$ & $\begin{array}{c}\sigma_{0} \text { bearing } \\
\text { /gon/ }\end{array}$ \\
\hline $\mathrm{G}_{1990}$ & 205.5600 & 5.5443 & 228.3615 \\
\hline
\end{tabular}

The BOL azimuth refers to the point $\mathrm{G}_{1006}$. Additionally, there are corrections in the tables for determining the appropriate mean errors in the determined azimuths.

Table 9. Recorded $\mathrm{A}_{0}$ azimuths and corrections

\begin{tabular}{|c|c|c|c|c|c|}
\hline Point & Date & Time & $\begin{array}{c}A_{0} \\
\text { azimuth } \\
\text { /gon/ }\end{array}$ & $\begin{array}{c}v \\
\text { /gon/ }\end{array}$ & $\begin{array}{c}v v \\
\text { /gon/ }\end{array}$ \\
\hline $\mathrm{G}_{1990}-\mathrm{G}_{1994}$ & $15 / 2 / 2018$ & $10: 10$ & 22.8007 & -0.77 & 0.59 \\
\hline $\mathrm{G}_{1990}-\mathrm{G}_{1994}$ & $15 / 2 / 2018$ & $10: 37$ & 22.8029 & 1.43 & 2.05 \\
\hline $\mathrm{G}_{1990}-\mathrm{G}_{1994}$ & $15 / 2 / 2018$ & $11: 24$ & 22.8008 & -0.67 & 0.44 \\
\hline $\mathrm{A}_{0} / 3$ & & & 22.8015 & {$[\mathrm{vv}]$} & 3.09 \\
\hline
\end{tabular}

Table 10. Recorded azimuths A and corrections

\begin{tabular}{|c|c|c|c|c|c|}
\hline Point & Date & Time & $\begin{array}{c}A \\
\text { azimuth } \\
\text { /gon/ }\end{array}$ & $\begin{array}{c}v \\
\text { /gon/ }\end{array}$ & $\begin{array}{c}v v \\
\text { /gon/ }\end{array}$ \\
\hline $\mathrm{G}_{1003}-\mathrm{G}_{1006}$ & $15 / 2 / 2018$ & $15: 03$ & 207.6425 & -0.45 & 0.20 \\
\hline $\mathrm{G}_{1003}-\mathrm{G}_{1006}$ & $15 / 2 / 2018$ & $15: 50$ & 207.6434 & 0.45 & 0.20 \\
\hline $\mathrm{A} / 2$ & & & 207.6430 & {$[\mathrm{vv}]$} & 0.41 \\
\hline
\end{tabular}

Table 11 lists the parameters needed to calculate the mean error of the arithmetic mean of the Uniform Trigonometric Cadastral Network (UTCN) BOL bearing.

Table 11. Parameters for calculating the mean error

\begin{tabular}{|c|c|c|}
\hline $\begin{array}{c}m_{x} A_{0} \\
/ \text { mgon/ }\end{array}$ & $\begin{array}{c}m_{x} A \\
/ \text { mgon/ }\end{array}$ & $\begin{array}{l}m_{x} \sigma_{0} \\
/ \text { mgon/ }\end{array}$ \\
\hline \pm 0.72 & \pm 0.26 & \pm 0.10 \\
\hline
\end{tabular}

Table 12 lists the resulting orientation measurement values the point $\mathrm{G}_{1003}$.

Table 12. Resulting orientation measurement values

\begin{tabular}{|c|c|c|c|c|}
\hline Point & $\begin{array}{c}A \text { azimuth } \\
\text { /gon/ }\end{array}$ & $\begin{array}{c}\gamma \text { conver- } \\
\text { gence } \\
\text { /gon/ }\end{array}$ & $\begin{array}{c}\sigma \text { bearing } \\
\text { /gon/ }\end{array}$ & $\begin{array}{c}m_{x} \sigma \\
\text { /gon/ }\end{array}$ \\
\hline $\mathrm{G}_{1003}$ & 207.6430 & 5.5607 & 13.2194 & \pm 0.77 \\
\hline
\end{tabular}

By orientation measurement, the UTCN BOL bearing (size 13.2194 gon) with the mean error of the arithmetic mean $\pm 0,77$ mgon was determined at the point $G_{1003}$.

Since the BOL between $G_{1003}$ and $G_{1006}$ was on the surface, it was possible to specify coordinates for both points. The coordinates were determined by the accurate 
traverse, followed by determining the bearing $\sigma_{x, y}$ In Table 13, both directions are compared.

Table 13. Bearing comparison

\begin{tabular}{|c|c|c|}
\hline $\begin{array}{c}\sigma \text { bearing } \\
\text { /gon/ }\end{array}$ & $\sigma_{x, y}$ bearing & $\begin{array}{c}\Delta_{\sigma-\sigma x, y} \\
\text { /gon/ }\end{array}$ \\
\hline 13.2194 & 13.2193 & 0.10 \\
\hline
\end{tabular}

\section{Conclusions}

Both cases of orientation measurements were carried out using the procedure described in Chapter 3. Based on the measured values, the respective UTCN bearings of the BOL that were being determined were calculated. At the BOL formed by the point $\mathrm{G}_{5693}$, the UTCN bearing (size 122.1493 gon) was determined with the mean error of the arithmetic mean $\pm 1.07 \mathrm{mgon}$. At the BOL formed by the $\mathrm{G}_{1003}$ point, the UTCN bearing (size 13.2194 gon) was determined with the mean error of the arithmetic mean \pm 0.77 mgon.

As a result, this type of measurement is one of the most accurate methods of orientation carried out in underground spaces (Decree No. 435/1992 Coll, n.d.). The significant advantage of orientation with gyrotheodolite is the fact that the orientation is determined by absolute values and does not depend on the Earth's magnetic field and its disturbances. It could also be used in orientation measurement of long polygon programs when building geodetic controls in places where no other technology can be used.

\section{References}

Bezdíček, V. (2016). Připojovací a usměrňovací měření na dole ČSM. Technická univerzita Ostrava. Retrieved from http:// hdl.handle.net/10084/115635.

Černota, P., \& Staňková, H. (2014). New methods of conducting connecting surveys and orientation measurements in mining works (1st. ed.). Košice: Technická univerzita v Košiciach.

Decree No. 435/1992 Coll. (n.d.). Of the Czech mining authority on mining measuring documents in mining activities and some activities carried out using mining methods, as amended. Retrieved from https://www.zakonyprolidi.cz/cs/1992-435

Neset, K. (1967). Důlní měřictví. II, Měření výškové, připojovací a usměrňovací, měření vytyčovací. Praha: SNTL - Nakladatelství technické literatury.

Novák, Z., \& Hánek, P. (1995). Geodézie v podzemních prostorách. Praha: České vysoké učení technické.

Sokkia Instruction. (n.d.). Instructions for use of SOKKIA GYRO $X$ devices. Retrieved from https://cn.sokkia.com/sites/default/ files/sc_files/downloads/gyro_x_ii_e_0.pdf 